4. Прогиозирование исхода заболевания с учетом результатов реализации лечебно реа билитационных мероприятий.

5. Аннамическое наблюделие за больным. асобенно в течение перлого тола nосле щристула

Реали:ацию рскоменауемой программы целесообразно проводить в УсАониях ПоликАи никя или областного (1ородското) эщияепто могического центра.

\section{AUTEPATYPA}

1. Болgырев А.И. Dлилепсик у взрослах.-M Мелниина, 1984.-288 с.

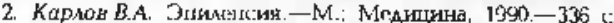

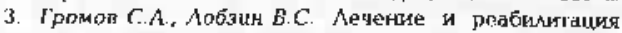

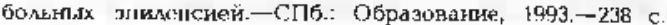

4. Громов C.A. Реабиитация бомитг эпилепсией. А.: Медицина, 1987.-176 c

Ilocrymat 12194in

\title{
C.A.Громов, E.B.Картаиева
}

\section{СОЗРЕМЕННЫЕ ПІОДХОДЫ К ТЕРАПИИ РАЗЛИЧНЫХ ТИПОВ ИЗМЕНЕНИЙ ЛЗҢНОСТИ У БОЛЬНЫХ ЭПИЛЕПСИЕЙ}

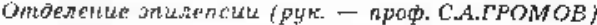

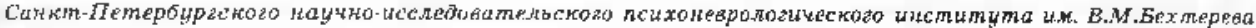

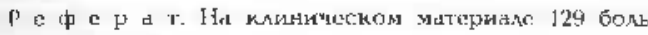
ңых эпилепсисй с изменениями лимнсти рассматрнвакот ся воцросы оптимиации Аифференцировацной терапии нынвленного психнческого мефекта. Приводтся ноная систематизация измененй ииности: обоснояндастся ]із

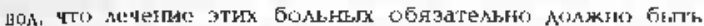

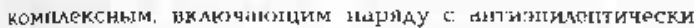
ми щрепаратоии и ряд лскхотропнаг средств.

\section{(. A. Громов, L.B Kapmauena}

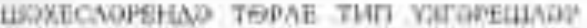

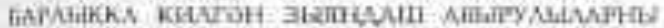

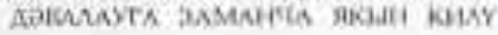

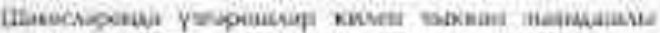

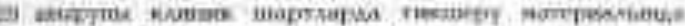

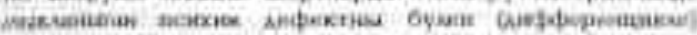

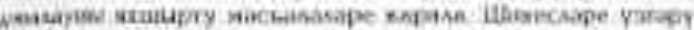

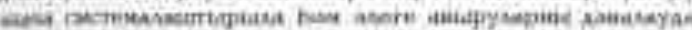

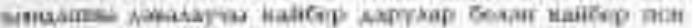

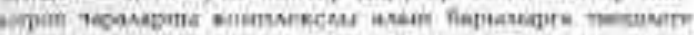

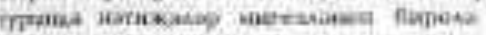

\section{S.A.Gromov, E. V.Kurtashevi}

PRESENT'LAY METHIODS OF THERAPY OF DIFFERENT TYPES OF MODIFICATION OF PERSONALITY IN EPILEPTICS

The question of optimization of differentialed therapy of revealed psyclic defect is discussed on clinicat material of 129 epileptics with modification of personality. New systematization of modificatuon of personality is given and the conclusion that treatrment of such patients must necessarily be complex, including a number of psychoartive drigst. is justified.

и зменения Аичности $(\mathrm{L} \Lambda)$ в хлинике эпи Аепсии Являются ОАним Из веАущиХ симп томов заболевания и встречантся в невро лотической грактике ме так уж реАко, хотя, как показывает наш опьт, неврологи их часто не регистриругт и не лечат. Традиционно в
Антературс описылается классичсский тил этих изменений, лсихплатологические фено мены, развивающиеся при мииепсия вслеА ствие органичсского поражения раздичных gтдслов мозга $|4,6,7,10,14|$. В то же время

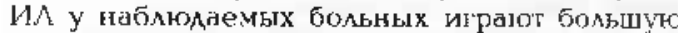
роль в клинической картине заболеюанин, рассматривағотся как психичсский дефеет и Часто Асзорганнзуют болыного сильлее, чем цриладки. Поэтому разработке лечения э'юх Прояндений заболешания в отһеленин эпилег сии институа им. В.М.Бехтерева последние

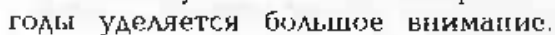

В то время қак лечение эпилептческих

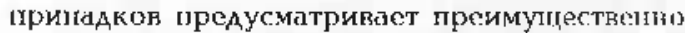
медикаментозную терапию, лечсбиыс мсро лрия'кя по купировалијо пгихичсского Ас фјекта включаюо кроме лекарствениых мето дов घңд и психосоциальнье и лсихотерапев гические воздействия, Сейчас становится со вергенно очевидным, чло вонросы изучения Акчиости и ее измецений принадлежат к иаи более актуадыны проблемам савременности. являясь объектом исследования многих науч

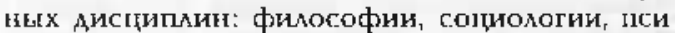
хологии, Ігсихиатрия и Ар. Аичность кажАого болжного нешонторима, определяется разными моментами. Часто на практике мы встрсчасмся с сочетанисм черт разных тилов изме пенИй АИчности. Их формирондние обусАов лејз как эноленными (генетичесқими, пато гелетическими), так и зкзогенными фактора ми (особенностяня воспитания, средой оби тания, игтеллектом и Ар.]. Хорошо известно, что эПилептоИАные черті АИчности ОАНиМ помагали Аостичь высокого, главенствукщего положения, АрУтим вреАилн и преврапали их в сутяг, преступников, алкоголиков и т.А.

Основными ЗаАачами нсслеАования яВИлись выделение и систематнзация различных 
типов ИА у больнџाх эпияспсией, ртзработка адекватной дифференцированной тералии с учетом гипа $И \Lambda$, вида припадков и Арутих особенностсй болезненного процесса.

Объектами нсследования послужили 129 больных эпияпсией с ИА в возрасте от 1.5 до 49 мет с Аавностью заболепания от I года до 33 лет, страдазиии разными видами эгин мептических пришадков. Мужчин было 68 $(52,7 \%)$ женцинн - $61 \quad(47,3 \%)$

Прозеденные исследования позволили вы делить 151, кроме "Тйичного" аля энислсии (ИАЭ), еце 4 смешанных тица изменений лич ности при этом заболсвагии: элилегтондно истероИАНЫЙ (ИАЈИ), эІилеПтОИАно-неустоЙ чивый (ИАЭЈ), эПияеПтоиАюО-цикАонАный (ИАЭЦ) и эпилеЛтОНАНО-ШизонАнЫЙ (ИАЭШ) Приведем их кра']кую характеристику

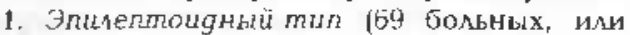
$53,5 \%$ ). Осцонндми цертами этоно тина явля Іотся тутолодвижность, замедменност'b, вязкость, пнертнотт нсихически шроцессов и склог

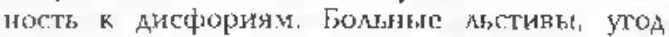
лизы и в то жс премя очень улряны. стеличны в достижении своих целей, скАоны к Іравдо искательгтву, сугяжничеству, крайгіе элопа

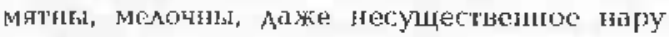
шегие заведенноч ими порядка мюжет выз ватв бурнт,й аффективньй разряд. Аффсктиз

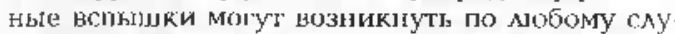
чайному Поводу, явивпемуся "последней кап мей", они отдичаютси Болынсй продомжитемь ностью; больные очень агрессивны, жестоки. Они склониє к злоулотреблениго алкоголем, предпочитают крегкие Папитки (Водку, сиирт) в больших количестыах, чтобы Аостичь силь ного опьянения. Толсралтность х спиртюому. как пранияо, внгсокая. Прием алкоголя може'т спровоцировати цазвитие Аисфории.

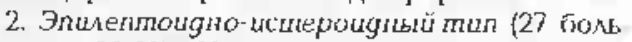
ных, или 20,9\%). "Татее наблюдается у женщин $(81,5 \%)$. Больные вкрадчивл, слащавы, утоА ливы, стараются произвести лучшес впехатление, вціставить себя в более выгодном све те, показать, как их кюбят окружающцие, сколько Аобрых Аел они совершияи. Вместе с тем эгоистичны, претенциозны, скАонны к Аемонстративному повсАению, стеничнш, гтре мятся Подчинить окрУжаюещих их АюАей, скАонны симуАировать припадки Аля Аостижения свонх целей, особенно в семье. Играя роль страдаяғтев, могуг часами плакат'ь “Аля ясчачего врача", предьявлять много жалоб на боли и нелриятіье ощущения в јаздичных частях тела, что порой ошибочно трактуется как астеногеротический синдром. Жалея больных, многие врачи соверша́ют типичную ошибку, начиная выполнять все их требова ния: необоснованно проводят множество не нужных обследований, отіускают больных Аомой и т.А. что привоАит $K$ Полной Аекомпенсации и социальной Аезалаптации этих пациентоп. В результате такой "доброты" многие трудоспособные больные становятся инваяидами, Аеспотами ls семье и в тех лечебных учреждениях іАе наблюдантся.

3. Эnunenmougho-kеустойчubый mun (15 бомь ных, ияи 12,2\%). Большуг часть болыных $(73,3 \%)$ Состанлягт мужчины. Этот тип ИА назван єами по аналогии с неустойчивелм тином Лсихо патий [8, 9]. Больные эйфоричны, их суждс ния летковесиы, оци как бы "лаывуг to те чению", примыкая к более пктивным Аицам. Часто менякт мсста учебы, работы, так как блгтро разочаронываются в своем выборе. У них поныпена тяга к развлечениям, праздности, бездельо. Аетко, не задумываяс ются на шредложсіия Арутих Аиц совериить любой асоциальньй постугік: совершнит меА кую кражу, принять наркогические средства

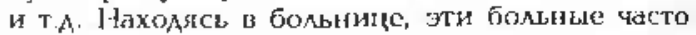
нарушают режим, затем извиняктся, ннешне Іроизнодя вгечатлелие ГАубоко раскииваю. щихся людей, и тут же инозь совернағот асо-

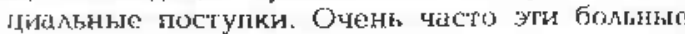
становяту алкогомиками и наркоманами

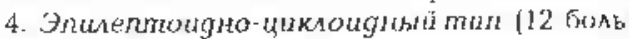

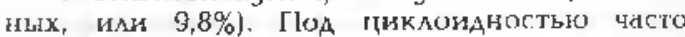
поразумеваюr относитсльно Аегкие случаи Маниакально депрессившог Ігиказд, ставя IоА сомкение гуцествование подоных психиче:ких изменений в рамках Аругих заб̆олењаъий. Суцествует мнение, что Аетрессившые состояния У Больных эпилелсисй обнчно тюихогенного происхождегия, внражены д; легкой форме н наступают только в связи с силь-

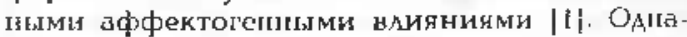
кю Наши Наблюдения Показали, что у ряда больных эпиленсией наблюдаются бесіричилпие цикличегкие изменепия эмоционалынго фона как ша зенсихотическом урозле ло тигу субдепрессий или гипоманиакальных состоя ний, так и достигаюцие степепи ијраженых психических нарушений: дешессивныс состояния С элементами виталхной тоски, пльра женгой апатией, бреАовыми ндеями самооб винения с появлением истинных суицидных мыслей и намерекий, с явлениями Аетерсона дизации, астенодепрессинные состозиия и Ар.

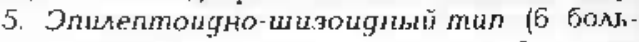
ных, ияи 4,7\%). Больные этого типа болыную часть врекени проводят за чтением книт или в ігстели, притворяясь спящими, чтобы их "оставнди в покое". Они мното читают о своем заболевании и, как правило, имект собственную концепцно его развития, резонерствуя об этом; проявяяют крайнее упримство, всег да оставаясь "при своем мнении", Внсшне производят впечатяение чудаков, странных, инфантияьных. Как правихо, сами к контакту с окружающими не стремятся, однако могут вдруг проянить крайнюю назойливость и бес тактность, отстаивая свое мнение. Недостаток общения компенсируется увлечениями, при которых они проявляют порой удивительную стеничность (юимнастика йоюов, карате, куАз туризм, ларапсихология, особые Аиеты, голо Аание), многие обнаруживают у себя зкстра 
сенсорные способности и т.А. Аюбнмое увле чение может заниматы все свободнос нремя. при этом больные бывают крайне пунктуаяь ны. педантичңы.

Аи ныяснения воnраса о возможной пато генетической связи припадка и развивпюцих ся ИА мы горовели их корреляционный анализ. Результаты предстаплены в табл. 1.

$$
\tau \text { a } 6, x \text { и пा а } 1
$$

Распредтелене больных по видам шрипадков н грушпах с разнмми тиламм измекекнй личности

\begin{tabular}{|c|c|c|c|c|c|c|c|c|}
\hline \multirow{4}{*}{$\begin{array}{l}\text { Tив } \\
\text { нзме: } \\
\text { Іетвй } \\
\text { мнчно- } \\
\text { сти }\end{array}$} & \multicolumn{8}{|c|}{ Вим припаяков } \\
\hline & \multirow{2}{*}{\multicolumn{2}{|c|}{$\begin{array}{c}\text { Парциаль- } \\
\text { เЋые: }\end{array}$}} & \multicolumn{4}{|c|}{ Гertepanusouafnde } & \multirow{2}{*}{\multicolumn{2}{|c|}{$\begin{array}{l}\text { CMellall } \\
\text { I TाIe }\end{array}$}} \\
\hline & & & \multicolumn{2}{|c|}{ Aбx:arick } & \multicolumn{2}{|c|}{$\begin{array}{c}\text { Cyяорож- } \\
\text { rlwe }\end{array}$} & & \\
\hline & a6c. & $\%$ & 360 & $\%$ & a $6 \mathrm{c}$. & $\%$ & $₫ 6 c:$ & $\%$ \\
\hline 1. $K \lambda \mathrm{J}$ & 32 & 46,4 & 15 & 21,7 & 47 & 683,1 & 25 & 36,2 \\
\hline 2. КАวИ & 11 & 40,7 & - & - & 25 & 93,6 & 9 & 33,3 \\
\hline 3. WЗH & 8 & 53,3 & 一 & - & 13 & 85,7 & $\mathfrak{G}$ & 40.0 \\
\hline 4. ИハЭЦ & 4 & 33,3 & 7 & 58,3 & 11 & 91,7 & 9 & 75,0 \\
\hline 5. ИАЭШ & 5 & 83.3 & - & - & 5 & 83,3 & 4 & 66,7 \\
\hline
\end{tabular}

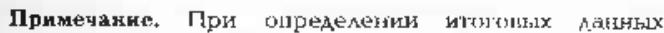
необходимо угитгпать, что $у$ некоторых больнах были смешаноне притадки.

Как видно из табол. 1, чанбоньшее коми чество больных с ИА разиға титоп страдало генерализованными суАорожными припалка ми, абсаннсы наблюдались только в гругітах Больнык с ИАЭ и ИАЭН. Значительное коли"есзво больных г. ИАЭНІ гтрадало парциальными припадками со сложной симптоматикой (83,3\%). В грутпах больных с ИАЭЦ и ИАЭШ преобладали большые с. сочетанием различных форм пароксизмов. Следует гакже отметить что у $5(18,5 \%)$ больHLLX С ИЛЭИ НабАКАались диэнцефалыные пароксизмы, у бслыных других групп их не иызвлено. Таким образом, генерализоданные судорожные припадки чацие, чем Аругие виды приступов, сочеталис. с наличием ИА (от 68,1 Ао 91,7\%), такая же корреляция выявлегі В отношении сложных иарциальшых (височных) приступов $(85,7 \%)$.

ЭЭГ-обкледование больиш с ИА пाоказамо. что четкая пароксизмальная акгивность мозга выявляется у них чаще (у 93,9\%), чем среди всех больных эпилепсией. У 81 (62.8\%) больного акцент пароксизмальных изменений приходияся на ОАНО из полупкаий мозга, а у $48(37,2 \%)$ зарегистрированы генерализованные билатерально-сиіхроніные вспышки ак. тивности.

лечению разных форм эпилепсии посвя цена обширная литература, однако в ней подробно освепены лреимущественно вопросы, касающиеся применсния разяичных антиэияептических препаратов и их сочетаний. О медикаментозной коррекции психи ческих нарушсний при этом страдания упоминается Аишь вскользь, в основном ири купировании психотических состояний. Составляя конкретную терапевтическую программу мл больного эПилепсией, врач Аолжен अа'ть Је толsко точный нозологический АиаГноз, виА и частоту присгупов, но и характеристику личности болыного [2].

13 шастояцее время общепринято, цто медижаментозная тератия эпияепсии моджна быть комплексной. Оснонгая роль ири этом отводится противосудорожной терагии, кото рая назначается с учетом вида пароксизмов [3]. Јти сведения лредстаплешы нами на оснонании обобщенного опытӑ мечения боль. ных этилепсией отечественными и зарубеж пнми препаратами в табл. 2.

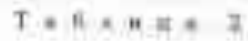

Эффект вноеть актизиялегтических прегаратов (в порядке убырания)

\begin{tabular}{|c|c|}
\hline 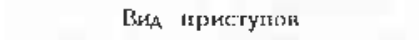 & 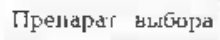 \\
\hline 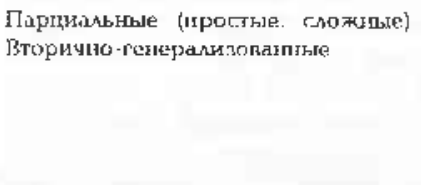 & 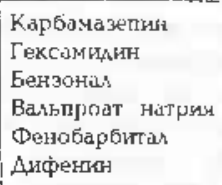 \\
\hline $\begin{array}{l}\text { Перяично-генеранизованные } \\
\text { (тонические, кионические, токи- } \\
\text { ко-кионические, атонические) }\end{array}$ & 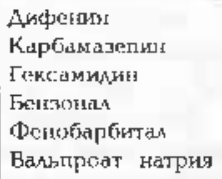 \\
\hline Абсанси (типичные, атишичные & 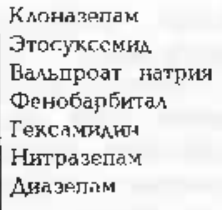 \\
\hline Mnokrurguteckit & $\begin{array}{l}\text { Barbiроат натрия } \\
\text { Kroназепам } \\
\text { (нитразецам) } \\
\text { Гексамадин }\end{array}$ \\
\hline
\end{tabular}

прв разньх видах эпилептических пристунов

Традиционио большинство авторов при купировании Аисфорических состояний гри эгикепсии предлагают пироко испояьзовать аминазин, оАнако, по нашему мнению, $x$ его исНОльзОВанию НадО ПОАХОАИть очень Аифференцированно. Нецелесообразно исподьзовать его при лечении больных с. выраженной заторможенностью, ригидностью и эначитель. шым сынжением игтсллектуально-мнестичес ких функций, а также в комплексной терапии миц с ИАЭЦ и ИАЭЩ, Так как он обладает Аепрессогенным действием и может способ сгвовать развитию так называемого лекарктвенного апатоабулического синдрома. Таким образом, применение прегарата может привести к ухудпенио пгихического состояния больного. Ислользование препарата в стан- 
Аартных Аозировкіх возможно мишь гир купировағии Аисфорий у Болыгाх с ИАЭИ и ИАЭН.

Ам трофриажтики развития дисфорий эна читедьно эффективнее ислтовзовать карбама зелин (финлепсин, тегретол) $0,4-1,2 \mathrm{mI} / с у$ су который обладает, как известно, нормогими ческим Аействием и редко выэывает побоч нюе эффекть. Болғным с выраженной гидро цефалией и головными болями с этюй же целью целесоборазно наздачаты, мочелонияе 1-2. paзa в reделzo.

Мы рекомендуем также пиироко нстользо вать карбамазепн? (финлепсич, тезретол) Аля профилактики развития Аетрессивных ссстояний. Антидепрессивное Аействие ег даже в больиих мозах при эниепсин отенк слабо пыражено, гоэтому мя кулировння детрес синцых состояний ми чапце применяем Аиу Iле средства: амитригтиян $0,05-0,3 \mathrm{mr} / \mathrm{cyт}$. мелилрамин $0,05-0,2 \mathrm{mr} / \mathrm{cyт}$, азафрен $0.05-$ $0,2 \mathrm{~m} / \mathrm{cys}$. При депрессин с. янлсниями Ае персонализациИ и брсдовыми нАеями само ббинелия целесоббцазно назначелие неболь IинХ Аоз нейролсштиков, обладакщй стиму лирукопим Аейстиием - френола 0,015--0,03 мГ/сут, солашакса $0,03-0,05 \mathrm{~mL} /$ сут, энонилӓ 0,05-0,075 мг/сут, а при тревожно-мегрессин ных состояняях - фелазепам 0,0015- 0,003 мг/сут, тизерцина 0,025-0,05 мг/сут. При उстенодетрессивных состояниях наибольший эсррект оказынает сочетанис френола 0,015$0,03 \mathrm{mr} /$ сут с сидлохарбом $0,01-0,03 \mathrm{mI} /$ суг.

При Аечения болыных с ИА.Ш, на нап взгляд, наибольший эффект Афет примелепие таких препаратов, как френолон 0,015-0,06 м\% $/$ сут, сонапакс $0,03-0,075 \mathrm{mr} / \mathrm{cyr}$ галоперияол $0,009-0,015 \mathrm{mr} /$ сут, тизерцит $0,01250,05 \mathrm{mr} /$ сут, фелазелтм 0,0015--0,003 иг/сут. При Алительном ириеме пренаратов отмечастся положигелыгая дигамика: болыныс становятся активлес, улучшакотя о'тошения в семьях и на работе.

Наиболыгие трудности позникают при лечении больных с ИАЭИ и ИАЭН. Как правияо, больные с. ИАОИ припькли к роли "страдамвцен"; симулируя в нужнелх ситуациух этилептические причадки, они извлекают из ээого внгоду: о них заботятся, освобож дант от повссаневных обязанностей и Объяснение враџом того, что эти припадки незпнлептической природы и что от них легко можно избавиться самостоятельно, по рой вызывает у больного реакцио протеста, так как мишаст его ореола тяжелобольного человекз. Иногда подобные јбъяснения при нодят к резкому УхуАшению состояния. При проведении психокоррекционной работы с этими болыными требуется много такта и терпения, однако никогАа не следуег потакать им, НАТи на ІоводУ. ПоскольКУ больнне край не стеничны, психотерапевтическис бесеАь эффективнее проводить после применения седативных средств: френолона, сонапакса,

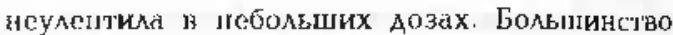
больных г ИАОИ Подаюютс Гипнозу, и это можно широко исподағовать при работе с НИМи.

Наимснее эффектинным оказызается ме чение больных с ИАЭН. Эти больные редко соблюдают рекомендации, склонны к уго'т. ребленик илкоголя и наркотикөн. Проведе ние психотераневтических бесел абсомютно незффективно. Позтому с первых дней прс бвинлия в клинике целесообразно назначать нейролептики: амигазин, тизерциг, галопе ридол, неулештия. В рнде случаев положи. тельный эффект Аает пнрогеная (начнная $25 \mathrm{MП} \Lambda_{r}$ постепенно увеличива'ть Аозу, на курс 15-20 :некц(ий). Пирогелал можно иироко испомзовать Также для преододения мекдрственной резистентности и при купи ровалии Аисфорических состояний. (ГЈред craвяенные выше р описательном варианте рекомендации по лечению $И \wedge$ жи суммиро вали в табА, 3.)

$$
\text { T a } 5 \text { औ }
$$

Рекоментуемыс грушты ирыларатов для дечекия больньх с различньми типахи НЛІ

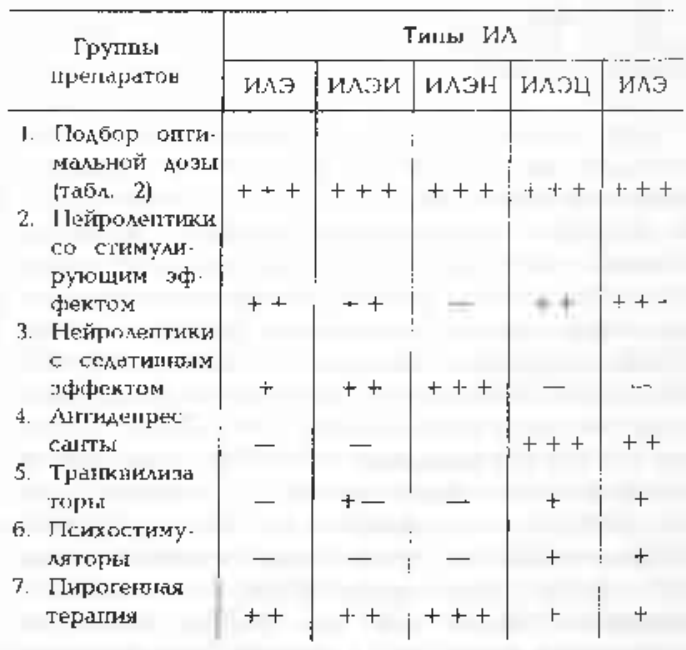

B Закаючение следует отметить, что в основе развития И $\Lambda$, возникающих у Боль шых элидепсией, видимо, лежит элилегтичес Кй̆ Иринадок с его дезинтегрируюшим влия нисм На Аеятельность ГОловног мозга. По. этому терапкя ИА должна быть преждс всел нанравлена на устранегие припадков а затем (иАи ОАговременно) ‥ нд возпикпий психический Аефект, Сам комплекс лечебных мероприятий по кутированијо ИЛ должен ВкАюцать в себя меАИхаментозные и неле карственные - п психтерапевтичсские и психосоциальные мерогіриятия. Опыт работъ с больнцми эпиленсией показывает, что ИА начинают регрессировать примерно через 2-3 года после полного кутирования при падков. 


\section{АИТЕРАТУРА}

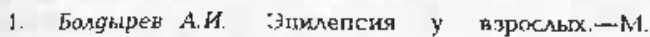
Медитыны, 1984.-288 с

2. Громон C.A. Гедбилитация больгх эпилегсиейA.: Медицита, 1987.-176 с.

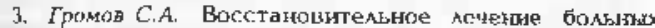

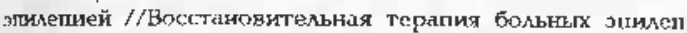
сией: С. науч. тр. /Психонеғроя. ин-т им. В.М.Бехте рена.-С.Г16., 1993. $\sim$ C. $7 .-34$

4. Аоброхомоно Т.А. Эмоциопальея латология при

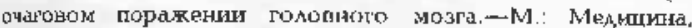
1974 .

5. Kopmausen E.B. Hовое is Аианностике и система

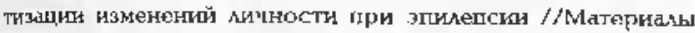
XJ] çeзаa психиатров Јосски.-M.r 1995.-№ 335

5. Комосова O.A. Локальные поражетия головного моза и гтруктура личности //Церебрлмике механизмы психинеских заболенанкй.-Кманюу. 1971,-Т.2,-С.121-123.

7. Колтонши А.Е., /иконенко Н.И. Хронитеские псики чпские изменения при тиияпсия и их занисимости от

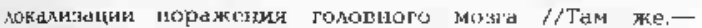
C. $153-\mathrm{t} .55$

8. Лачко А.Е. Лскхолатки н акцегпуақй харакіера

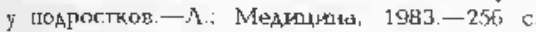

9. Аачко А.E. Подристковая психизтрия: Руховодстно Ам нрачей.-А.: Медияита, 1985.-416 с

10. Тец И.С. Китахо-психотатологические особеннос

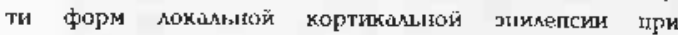

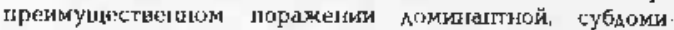
гантюой $и$ обеих темисфер головного млзна //Журн. невробатол. и психиат.-1977.-Bum.3.C.392-402

11. Якунши О.Н. Пскхокоррахгионная работа в гистеме восстановитеяничо лечения болынд энилепсией //Восстановительная терапия больных आлислсией: Сб. науч. тр. /Психигеврол. ин.т им. В.М.Бехтерева.-СПб. 1993 -C. $122-153$.

12. Pear D.M., Fedio P, Ouantilative andysis of interjectat behavior in temporal lobe epilepsy //Auch. of Nemrol.1977.-Vol.34.-P.454

13. Bickenbach $W$. Klinik und Elektroencefalograjnm der akuten epileptischen Psyctowen.-Diss.-B

14. Kohter $G$. Epileplische Psychosen //Foschr. Neurol Psychial. - 1973.-Bi.41, № 9.- S.496-509.

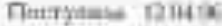

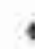

УAK 616.99:518.2

\author{
М.В.Ситарская, Л.А.Козлов, М.Ф.Исмазилов, Э.Р.Сафина
}

\title{
ВЕТЕТАТИВНАЯ РЕГУЛЯЦИЯ У ЖЕНЩИН \\ В ТРЕТЬЕМ ТРИМЕСТРЕ ФИЗИОЛОГИ'ЕСКОЙ БЕРЕМЕННОСТИ 11О ДАННЫМ МАТЕМАТИЧЕСКОГО АНАЛИЗА РИТМА СЕРДЦА
}

\author{
Кареора анушерстеа и гинекялюzиц № 1 (зав. - боч. КО.И.БОРОДИН).

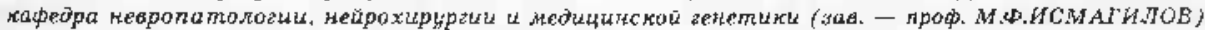 \\ Казалского госудирственного жеоццинского университета
}

$P$ e q e $p$ a $\mathbf{T}$. Провенено изучение вететативноло sомеостаза у здоровьг беременных в срок $30-40$ нел метолом карлиоитервалография. Обнаружено наличие

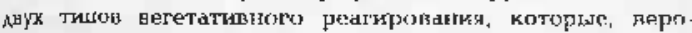
янно, янянотея варнантами нормы. Сделан вынод, 4 то даптационые ироцессы при физиологической беремен

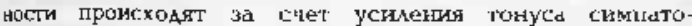

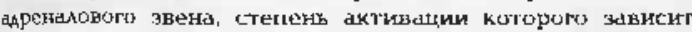

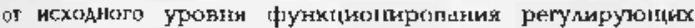
cисาем.

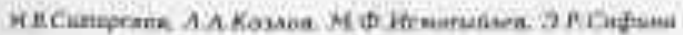

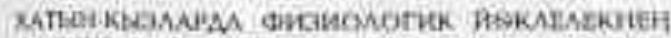

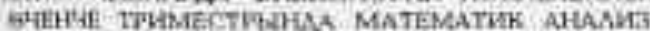

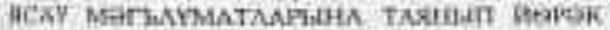

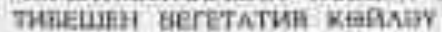

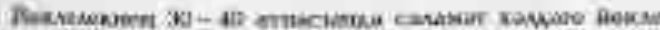

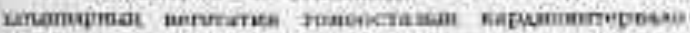

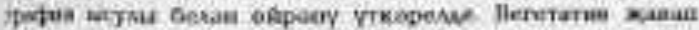

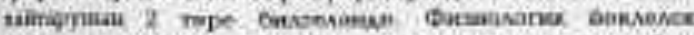

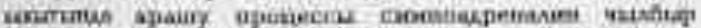

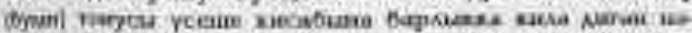

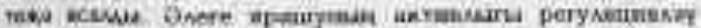

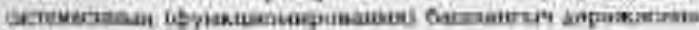
towke.
M.V.Sitorskaya, L.A.Kozjov, M.F.Ismagituv, E.K.Safina

VEGETATIVE REGIJLATION IN WUMEN IN THE THIRU TRIMĒSTEK

OF IPHYSIOLOGICAL PREGNANCY ACCORDING TU MATHEMATICAL ANALYSIS OF CARDIAL RYTHM DATA

A study on vegelative homenstasis in healthy pregnant women a! the tern of $30-40$ weeks was held by the raethod of cardiointervalography. Availability of two types of vegeta tive response was found, which are likely variants of standard response. A conclusion was made, that prucesses of adaptation in physiologic pregnancy are accounted by the growth of the tonicity of sympato-adrenalic link, decree of activation of which depends on initial level of functioning of regulating systems.

Момсіта НиАации Гиодного яйца в организме бсремениой происходит изменение нейрогуморальных процессов, направленных па адекватное обеспечспие жизнедеятельности развипағщегося плода $[12,14]$. Известіо, что аяалтационные реакұии у беременных сопровожАаются гиперкинетическим типом цир куляции, гиперволемией, усилением активнос- 